\title{
急性重症心不全に対する機械的補助循環の有用性と問題点
}

\author{
-IABP，PCPS 同時使用の経験一
}

\author{
田中久史柳谷晶仁数井暉 久*
}

\begin{abstract}
近年, 経皮的カニューレ，遠心ポンプ，人工肺を含めた全回路ヘパリンコーティングの経皮的心肺補 助装置 (PCPS) が, 急性重症心不全例の循環補助として急速に普及してきている. 今回，筆者らは， 5 例の急性重症心不全例に対し, 大動脈内バルーンパンピング(IABP) と全回路へパリンコーティング したPCPS を併用した。 いずれも大量のカテコラミン, IABPでも循環維持不能の症例であった。 PCPS 開始後は, 平均補助流量が約 $2.3 \mathrm{l} / \mathrm{min}$, 中等量のカテコラミンで血行動態は安定し, 良好な循 環補助効果が得られた。 PCPS 施行中, 賦活化凝固時間は低值で維持したが, 血栓形成, 出血などの 合併症は認められなかった。 4 例が離脱し，2 例は社会復帰している.PCPS の適応, 適用時期, 至適 流量などについては未だ議論のあるところであり, その施行に関しては慎重を要するが, 薬物療法や IABP の限界を越えた重症心不全に対し，IABP との併用は有効な治療手段であると考えられた。日 心外会誌 25 巻 2 号 : 80-85 (1996)
\end{abstract}

Keywords : 補助循環, IABP, 経皮的心肺補助(PCPS), 重症心不全, ヘパリンコーティング

\section{The Usefulness and Limitations of Mechanical Circulatory Assistance for Profound Heart Failure-Simultaneous Use of IABP and PCPS}

Hisashi Tanaka, Akihito Yanagiya and Teruhisa Kazui* (Department of Cardiovascular Surgery, Nikko Memorial Hospital, Muroran, Japan and Second Department of Surgery, Sapporo Medical University School of Medicine*, Sapporo, Japan)

In 5 cases of profound left ventricular failure, simultaneous application of a percutaneous cardiopulmonary support system (PCPS) in which the entire circuit was coated with heparin, and intra-aortic balloon pumping (IABP) were performed. No case responded to therapy consisting of large amounts of inotropic agents, followed by IABP. With the assistance of the PCPS (mean flow rate $2.3 \mathrm{l} / \mathrm{min}$ ) combined with moderate doses of inotropic agents and IABP, the hemodynamics of all 5 patients were stabilized. Using low amounts of heparin, the activated coagulation time during PCPS was maintained between 150 and 200 seconds. No complications directly related to this procedure such as thromboembolism and bleeding were observed. Four cases have been successfully weaned from the PCPS. Of the four, two cases are long-term survivors and are currently functioning normally in society. At present, the indications, optimum parameters for PCPS flow rate, and when to start weaning from the PCPS have not been established. However, we conclude that simultaneous use of PCPS and IABP is useful to maintain adequate systemic circulation in cases not responding to medication and IABP. Jpn. J. Cardiovasc. Surg. $25: 80-85$ (1996)

急性心筋梗塞や開心術後の薬物抵抗性重症心不 全に対し，積極的に機械的補助循環法が用いられ ている ${ }^{1,2)}$. 補助循環法のなかでも，大動脈内バル ーンパンピング(intra-aortic balloon pumping: IABP) は, Kantrowitz の報告以来, 適応も拡大し 繁用されており，その有用性は確認されてい

1995 年 3 月 6 日受付, 1995 年 6 月 8 日採用

日鋼記念病院心蔵血管外科 $\overline{7} 051$ 室蘭市新富町 1-5-13

* 札幌医科大学第 2 外科
$ろ^{3 \sim 5)}$. 一方，重症ショック，心停止例に対する蘇 生措置やハイリスク患者の経皮的冠状動脈形成術 (percutaneous transluminal coronary angioplasty：PTCA) 時の循環補助 (supported PTCA) として, 経皮的心肺補助法 (percutaneous cardiopulmonary bypass support: PCPS)が臨 床応用されるようになり，その効果が期待されて いる ${ }^{6 \sim 11)}$.

今回, 筆者らは, 強力な薬物治療, IABP でも循 
環を維持できなかった 5 例の急性重症心不全に対 し，全回路ヘパリンコーティングしたPCPS を併 用し，その有用性と問題点について検討したので， 若干の文献的考察を加えて報告する。

\section{対象と方法}

対象は, 1993 年 5 月からの 1 年間に, 心原性シ ヨック，低心拍出量症候群(low output syndrome：LOS), 体外循環離脱困難例などの急性 重症心不全に対し，IABP と PCPS を同時使用し た 5 例である。その内訳は，男性 3 例，女性 2 例 で，年齢は $47 \sim 76$ 歳，平均 63 歳であり，全例， 虚血性心疾患であった(表 1 )。

症例 $1,2,3$ は, 左冠状動脈主幹部 (left main trunk：LMT) 病変で冠状動脈バイパス術 (coronary artery bypass grafting : CABG)を施行し た症例である。手術は，3 例とも大伏在静脈を用 い, 前下行枝と回旋枝への 2 枝バイパス術を行っ た. 大動脈遮断時間は 60 分以下であったが, 手術 前よりカテコラミン投与, IABP による循環補助 を行っており，術中，大量のカテコラミン投与， IABP 施行下に体外循環離脱を試みたが, 収縮期 圧は $100 \mathrm{mmHg}$ 以下で血行動態の維持は難しか った。よって, 体外循環離脱困難と判断し，また， いずれも LMT 病変であるということも考慮し PCPS を施行した. 離脱試行時のカテコラミンの 投与量は，3 例とも dopamine(DOA), dobutamine (DOB) が $15 \mu \mathrm{g} / \mathrm{kg} / \mathrm{min}(\gamma)$, noradrenaline (NA) が $0.3 \gamma$ 以上であり, 肺動脈圧も収

表 1 Five patient's profiles treated with IABP and PCPS for profound heart failure

\begin{tabular}{lccl}
\hline Patients & Age & Sex & \multicolumn{1}{c}{ Diagnosis } \\
\hline 1 & 60 & F & Unstable angina (LMT 90\%) \\
2 & 73 & M & AMI (LMT 99\%) \\
3 & 57 & M & AMI (LMT 99\%) \\
4 & 47 & M & Coronary spasm (Post-CAGB) \\
5 & 76 & F & Post-infarction VSP \\
\hline
\end{tabular}

IABP : Intra-aortic balloon pumping, PCPS : percutaneous cardiopulmonary support, AMI: acute myocardial infarction, LMT: left main trunk, CABG : coronary artery bypass grafting, VSP: ventricular septal perforation.
縮期で $35 \mathrm{mmHg}$ 以上，肺動脈楔入圧も 18 $\mathrm{mmHg}$ 以上であった。

症例 4 は, CABG 後(集中治療室入室直後)に冠 摹縮を発症し, 心原性ショックから心停止に至っ た症例である。開胸心マッサージを施行し蘇生し

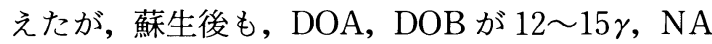
が $0.5 \sim 0.8 \gamma$, Adrenaline が $0.3 \gamma$ 前後と大量の力 テコラミンを使用していた。また IABPによる循 環補助も行ったが血圧は $90 \mathrm{mmHg}$ 以下であり, PCPS による循環補助が必要であると判断した。

症例 5 は, 急性心筋梗塞 (acute myocardial infarction：AMI) 発症後 1 日目に心室中隔穿孔 (ventricular septal perforation: VSP) を発症 し，心原性ショックに陥った症例である.VSP 発 症直後より大量のカテコラミン $(\mathrm{DOA}, \mathrm{DOB} \geqq$ $12 \gamma, \mathrm{NA} \geqq 0.5 \gamma)$ 投与, IABP による循環補助にて も血圧は $90 \mathrm{mmHg}$ 以下であり, 循環維持のため には PCPS による循環補助が必要であった。患者 は, VSP 発症後 2 日目に手術(VSP patch closure)を行ったが, LOS のため体外循環から離脱 できず，VSP 発症直後より施行していたPCPS により循環を維持し続けた。

機械的補助循環法については, IABP は左大腿 動脈より挿入し，PCPS は右大腿静脈経由右房脱 血，右大腿動脈送血にて施行することを原則とし た(図 1 ). PCPS の送血カニューレは 15〜 17 Fr., 脱血カニューレは 17〜19 Fr.のものを用いた。 PCPS システムは, 経皮的送脱血カニューレ, 遠心 ポンプ，模型人工肺を含めた全回路をへパリンコ ーティングした完全閉鎖回路 (Carmeda Closed Chest Support System : Carmeda AB 社製)を用 いた. PCPS 施行中は, 賦活化凝固時間 (activated coagulation time: ACT)の值を 150〜200秒に コントロールするようにへパリンを投与した(開 始時, 回路内に 1,000 単位注入, 体内に 2,000 単 位を静注し，以後，間欠的に 1,000 単位を投与し た).送脱血カニューレを除いた遠心ポンプと人工 肺を含む回路は，48 時間ごとに交換した。PCPS 施行中は, 平均動脈圧を $80 \mathrm{mmHg}$ 以上, 中心静脈 圧を $8 \sim 12 \mathrm{~cm} \mathrm{H}_{2} \mathrm{O}$, 混合静脈血酸素飽和度を 65\%以上, 動脈血(右橈骨動脈)酸素飽和度を $95 \%$ 以上に保つょうに管理した。離脱時の送脱血カニ 
ユーレの抜去は, 大腿動静脈の穿刺部位を外科的 に修復した。

\section{結 果}

各症例の PCPS の補助流量, 施行期間, 離脱の 有無，転帰を表 2 に示した。いずれの症例とも PCPS 開始後は, カテコラミンは中等量(DOA,

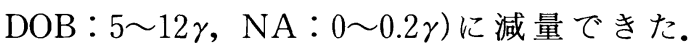
PCPS の補助流量は $1.5 \sim 3.0 \mathrm{l} / \mathrm{min}$ で, 5 例の平 均は $2.3 \mathrm{l} / \mathrm{min}$ であった。補助循環時間は

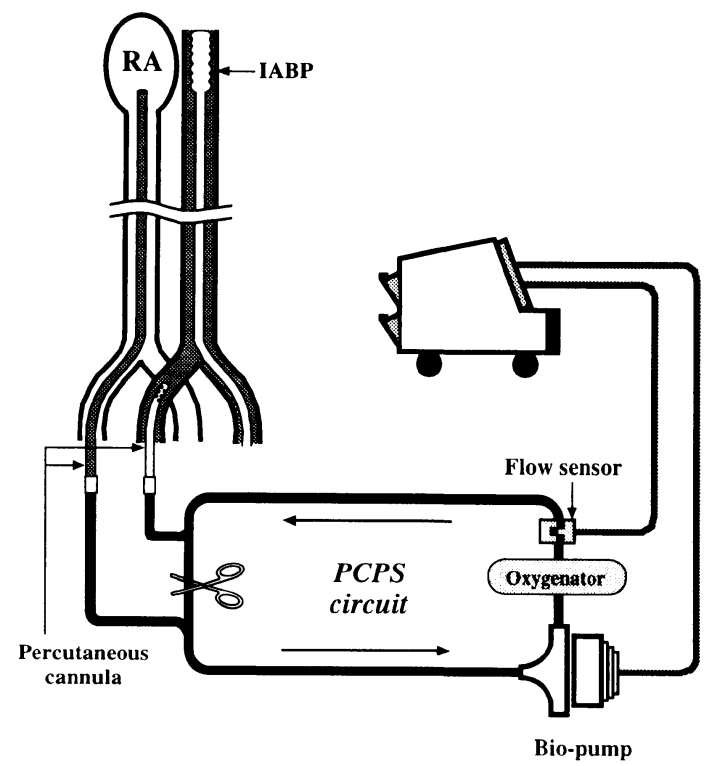

図 1 Illustration of mechanical circulatory support methods

RA : right atrium, IABP : intra-aortic balloon pumping, PCPS : percutaneous cardiopulmonary bypass support.
18〜106 時間, 平均 62 時間であり, PCPS からの 離脱が困難と判断し途中で中止した症例 5 を除い た離脱例では, 平均 51 時間であった. 離脱に関し ては，自験例では図 2 に示した基準を参考に行っ た. 4 例において離脱に成功したが，離脱した 4 例中 2 例 (症例 1,2 ) は, 肝不全と多藏器不全で おのおの，術後約 1 か月および 7 日に死亡した。 症例 3,4 は, 離脱後順調に経過し, 現在社会復 䚻している，離脱しえた 4 例においては，溶血， 感染, 出血, 血栓塞栓症, 下肢虚血などの PCPS に 起因する合併症は認められなかった。

$$
\begin{gathered}
\text { 考 察 } \\
\text { 経皮的送脱血カニューレ, 遠心ポンプ, 膜型人 }
\end{gathered}
$$

\begin{tabular}{|c|c|}
\hline $\begin{array}{l}\text { medium amount of } \\
\text { catecholamines }\end{array}$ & $\left(\begin{array}{l}\text { DOA }<15 \gamma \\
\text { DOB }<15 \gamma \\
\text { NA }<0.2 \gamma\end{array}\right.$ \\
\hline IA B P & $1: 1$ \\
\hline PCPS assist flow rate & $0.5 \sim 1.0 \mathrm{~L} / \mathrm{min}$ \\
\hline \multicolumn{2}{|l|}{$\downarrow$} \\
\hline MAP & $\geqq 80 \mathrm{mmHg}$ \\
\hline PCWP & $<18 \mathrm{mmHg}$ \\
\hline $\mathrm{S}_{\mathbf{v}} \mathrm{O}_{2}$ & $\geqq 65 \%$ \\
\hline \multicolumn{2}{|l|}{ good clinical impression } \\
\hline
\end{tabular}

図 2 Referential criteria for weaning patients from PCPS in our cases

PCPS : percutaneous cardiopulmonary bypass support, IABP : intra-aortic balloon pumping, DOA : dopamine, DOB : dobtamine, NA : noradrenarine, MAP : mean arterial pressure, PCWP : pulmonary capillary wedge pressure, $\mathrm{S}_{\bar{v}} \mathrm{O}_{2}$ : mixed venous oxy. gen saturation.

表 2 Clinical results of PCPS

\begin{tabular}{ccccl}
\hline Patients & $\begin{array}{c}\text { Assists flow } \\
(1 / \mathrm{min})\end{array}$ & $\begin{array}{c}\text { Duration } \\
\text { (hours) }\end{array}$ & Weaned & \multicolumn{1}{l}{ Outcome } \\
\hline 1 & $2.5-3.0$ & 18 & Yes & Died (liver failure) \\
2 & $1.5-2.0$ & 97 & Yes & Died (MOF) \\
3 & $2.2-2.8$ & 49 & Yes & Survived \\
4 & $1.9-2.5$ & 41 & Yes & Survived \\
5 & $2.0-2.5$ & 106 & No & Died (termination) \\
\hline Average & $: 2.3$ & 62 & & \\
\hline
\end{tabular}

PCPS : percutaneous cardiopulmonary support, MOF : multiple organ failure. 
工肺を含めた全回路へパリンコーティングの PCPS が開発され，急性重症心不全例の循環補助 として積極的に臨床応用されるようになってきて いる. PCPS は, 手術操作を要さず, 容易にかつ速 やかに循環補助を開始でき，しかも，流量補助が 可能であり心停止に近い状態でも全身循環の維持 が可能である。しかし，その適応，開始および離 脱時期，至適流量などについては，いまだ議論の あるところである，今回，著者らは，薬物治療に 抵抗する急性重症心不全例に対し，圧補助として のIABP とともに流量補助として全回路へパリ ンコーティングした PCPS を適用し，その有用性 と問題点について検討した。

PCPS の非侵襲性, 迅速・簡便性, 強力な補助循 環作用を考慮すると，主に重症例の supported PTCA, 緊急時の心肺蘇生, 心原性ショックや体 外循環離脱困難例，一時的な肺機能低下例などが 適応と考えられる ${ }^{6 \sim 11)}$. さらに補助人工心臓 (ventricular assist device : VAD) または心移植 へのブリッジとしても応用できる ${ }^{12,13)}$. 自験例に おいても, 全例, 大量のカテコラミンによる薬剤 治療，IABP だけではコントロールできない急性 重症心不全例に対し用いており，PCPSの適応で あったと考える. IABP と PCPS の併用により中 等量までカテコラミンを減量でき，血行動態を安 定させることが可能となったが,これは, IABP と PCPS の有益な作用が相乗的に働いたためと考え られる.つまり IABP の後負荷軽減, 冠灌流増加, 拍動流が得られるなどの作用と，PCPS の前負荷 軽減，心筋酸素消費量の減少，全身循環の維持な どの作用が効果的に働いたためである12 16).よっ て，PCPS は単独で使用するより IABP と併用し たほうが効果が大きく望ましいと思われた。 今回 は，5例中 4 例においてショック状態あるいは LOS から脱却できたが，1例(症例 5 ) は心筋傷害 の程度が強く，現行の治療を継続しても回復が望 めなかったため 106 時間で中止した。これらのこ とは, PCPS が, 薬剤治療, IABP のみでは循環を 維持できない極度の重症心不全例に対し，救命の ための治療手段として有用であり，とくに短期間 の使用であれば，IABP との併用でVADにより 近い, 強力な新しい補助循環法であることを示唆
している.しかし，症例 5 のように心筋が広範囲 に不可逆的傷害を受けている場合は離脱は困難で あり，中枢神経系傷害のある場合も救命すること は難しい9 . したがって, 循環維持のためとはいえ 無制限に用いるべきではなく，その施行に関して は慎重を要すると考えられた。症例 5 の場合は, 今匡は治療を断念したが，長期循環補助を目的に $\mathrm{VAD} へ$ 移行も考慮すべきであったかもしれな い.このことは, 心移植を含め今後の課題である と思われた。離脱に関しても，自験例では，図 2 のような基準を設けて試みたが, PCPS は, 人工肺 および遠心ポンプに耐久性の問題があり長期施行 は難しい，とくに，膜型人工肺には血漿漏出の欠 点があり ${ }^{11)}$ ，今回は 48 時間ごとに交換した。した がって，できるなら早期に離脱することが望まし いと思われた。また，今後はより耐久性のある人 工肺の開発の必要性をも痛感した。

PCPS の補助流量を増大させると，心臓に対す る前負荷は一層軽減し心筋酸素消費量も減少す る。同時に動脈圧は上昇し，全身諸㵴器および末 梢の循環は維持されるが，左室に対する後負荷は 増加する、ショック状態からの脱却には体血圧の 上昇が必要である以上，ある程度の後負荷の増大 はやむをえないが,むやみに高流量とすることは， 後負荷を増大させるだけでむしろ心機能の回復を 阻害することになる ${ }^{7,16)}$.したがって, PCPS の補 助流量は, これら前負荷軽減, 循環動態改善, 後 負荷増大の作用を総合的に考慮し決定する必要が ある.服部ら ${ }^{14)}$ は, 静動脈バイパスの至適流量に 関し，一定の循環血液量の下では，満足な全身灌 流を得てしかも左心負荷が最小となる流量は 40 $\mathrm{ml} / \mathrm{kg} / \mathrm{min}$ であると報告している，自験例でも， 補助流量は, 平均 $2.3 \mathrm{l} / \mathrm{min}$ で, 体重当たりでは $38.3 \mathrm{ml} / \mathrm{kg} / \mathrm{min}$ となり服部らの報告とほぼ一致 している.

流量補助を必要とするような重症例，例えば開 心術後の体外循環離脱困難例, ショックに併発し たDIC 状態を示す症例などでは易出血状態にあ ることが多い.さらに機械的補助を行えば，血小 板, 血液凝固因子が破壊され出血傾向が助長され るため, ヘパリンの投与量は最小限にとどめ, ACTを低值でコントロールすることが望まし 
い. その点, 回路のへパリンコーティングによる 抗血栓化は, ヘパリン投与量の低減を可能にした。 また, 補体活性化の抑制, 血球成分破壊の抑制な どの効果が期待できるという報告もある ${ }^{17,18)}$. 自 験例でも，全回路へパリンコーティングされたシ ステムを用いたが, 出血, 血栓形成などの合併症 を認めることなく, 少量のへパリン投与により ACT 150 200 秒と低值でのコントロールが 可能であった。

\section{結語}

大量のカテコラミンによる薬剤治療, IABP に よる循環補助によっても血行動態が安定せず循環 維持ができなかった急性重症心不全例に対し, PCPS を伴用し以下の結論を得た。

1） IABP と PCPS の併用により, 中等量の力 テコラミンで血圧を維持し，血行動態を安定させ ることが可能であった。

2）全回路ヘパリンコーティングしたPCPS は, 出血などの合併症の点からも優れた循環補助 法である。

3）しかし，PCPS の適応，開始および離脱時 期, 至適補助流量, ならびに中止の判断などには 明白な基準がないため，その施行に関しては慎重 を要する.

稿を終えるにあたり，ご校閲いただいた札幌医 科大学医学部第 2 外科, 小松作蔵教授に深謝いた します。

\section{文献}

1) Matsuda, H., Matsuwaka, R., Kaneko, M. et al. : Analysis of clinical factors for survival after left and biventricular bypass using centrifugal pump following open heart surgery in infants and adults. Artif. Organs. 14 : 382-386, 1990.

2) Pae, W.E., Miller, C. A., Matthews, Y. et al. : Ventricular assist devices for post-cardiotomy cardiogenic shock. J. Thorac. Cardiovasc. Surg. 104 : 541-553, 1992.

3) Kantrowitz, T., Joenneland, S., Krakauer, J. S. et al.: Mechanical intra-aortic cardiac assistance in cardiogenic shock; Hemodynamic effects. Arch. Surg. 97 : 1000-1004, 1968.
4) Dunkman, W. B., Leinbach, R. C., Buckley, M. $\mathrm{J}$. et al. : Clinical and hemodynamic results of intraaortic balloon pumping and surgery for cardiogenic shock. Circulation 46: 465-477, 1972.

5）冨田喜文, 高野照夫：大動脈内バルーンパンピン グ. 集中治療 3: 223-229, 1991.

6) Phillips, S. J., Ballentine, B., Slonine, D. et al. Percutaneous initiation of cardiopulmonary bypass. Ann. Thorac. Surg. 36 : 223-225, 1983.

7) Vogel, R. A., Tommaso, C. L. and Gundry S. R. : Initial experience with coronary angioplasty and aortic valvuloplasty using elective semipercutaneous cardiopulmonary support. Am. J. Cardiol. 62 : 811-813, 1988.

8) Phillips, S. J., Zeff, R. H., Kongtahworn, C. et al.: Percutaneous cardiopulmonary bypass: Application and indication for use. Ann. Thorac. Surg. 47 : 121-123, 1989.

9) Hartz, R., LoCicero III, J., Sanders, J. H. et al. : Clinical experience with portable cardiopulmonary bypass in cardiac arrest patients. Ann. Thorac. Surg. 50 : 437-441, 1990.

10) Mooney, M. R., Arom, K. V., Joyce, L. D. et al. : Emergency cardiopulmonary bypass support in patients with cardiac arrest. J. Thorac. Cardiovasc. Surg. 101 : 450-454, 1991.

11）佐藤尚司，小林 享，平石泰三ほか：経皮的両心 補助を行い救命し得た急性心筋梗塞後重症心不 全の 1 例. 日胸外会誌 40：1907-1912, 1992.

12) Rithel, S. C., Swartz, M. T., Braun, P. R. et al. : Experience with an emergency resuscitation system. Trans. Am. Soc. Artif. Intern. Organs 35 : 457-477, 1989.

13）村上厚文，丹波 誠，久米誠人ほか：重症心原性 ショックに対するV-A バイパスの応用一 292 時 間におよぶ長期補助循環の経験一。人工臟器 22 : 615-619, 1993.

14）服部良二, 魏 啓明, 井村正史ほか：急性左心不 全に対するVA バイパスの循環補助効果に関す る実験的検討。日胸外会誌 35：483-490, 1987.

15) Bavaria, J. E., Furukawa, S., Kreiner, G. et al. : Effect of circulatory assist devices on stunned myocardium. Ann. Thorac. Surg. 49 : 123-128, 1990.

16）曽根孝仁，小山富生：心原性ショックにおける経 皮的心肺補助の役割. ICU と CCU 17: 235-243, 1993.

17) Mottaghy, K., Oedekoven, B., Schaich-lester, D. et al.: Application of surfaces with end point attached heparin to extracorporeal circulation with membrane lungs. Trans. Am. Soc. Artif. Intern. Organs 35 : 146-152, 1989. 
18) Videm, V., Svennevig, J. L., Fosse, E. et al.: Reduced compliment activation with heparincoated oxygenator and tubings in coronary bypass operations. J. Thorac. Cardiovasc. Surg. 103 : 806-813, 1992. 